\title{
Iron chelator, exopolysaccharide and protease production in Staphylococcus epidermidis: a comparative study of the effects of specific growth rate in biofilm and planktonic culture
}

\author{
Elwyn Evans, ${ }^{1} \dagger$ Michael R. W. Brown ${ }^{2}$ and Peter Gilbert ${ }^{1}$
}

Author for correspondence: Peter Gilbert. Tel: +4461275 2361. Fax: + 44612752396.

\footnotetext{
1 Department of Pharmacy, University of Manchester, Oxford Road, Manchester M13 9PL, UK

2 Pharmaceutical Sciences Institute, Department of Pharmaceutical and Biological Sciences, University of Aston, Birmingham B4 7ET, UK
}

\begin{abstract}
The growth rate of Staphylococcus epidermidis was controlled for populations growing as a biofilm and perfused with supplemented, simple-salts medium. Production of iron chelators, extracellular protease and exopolysaccharide (EPS) by these populations was assessed as a function of specific growth rate and compared to that by planktonic populations grown in the same medium within a chemostat. Perfused biofilms increased their iron chelator and protease production with increasing growth rate. Chemostat populations decreased their production of iron chelators with increasing growth rate, whilst showing much enhanced production of proteases at intermediate growth rates $\left(\mu, 0.15-0.25 h^{-1}\right)$. Production of iron chelator and protease was generally 2-50 times higher by biofilms than by planktonic populations. EPS production was low and relatively unaffected by growth rate for the chemostat cultures (about $0.2 \mu \mathrm{g}$ per unit cell mass) but high for the attached biofilms, particularly at slow growth rates (about $4 \mu \mathrm{g}$ per unit cell mass). EPS production within the biofilms decreased markedly with increasing growth rate. At growth rates of $0.35 \mathrm{~h}^{-1}$ and above, the levels of EPS for biofilms and planktonic populations were equivalent. The results of this study clearly indicate that growth as a biofilm markedly influences extracellular virulence factor production by $S$. epidermidis.
\end{abstract}

Keywords: Staphylococcus epidermidis, biofilms, exopolysaccharide, growth rate, virulence factors

\section{INTRODUCTION}

Staphylococcus epidermidis is a ubiquitous skin commensal of man and animals and an opportunistic pathogen associated with indwelling medical devices such as cardiac valves, prosthetic joints and pacemaker leads (Gristina et al., 1987; Marrie et al., 1982; Fidalgo et al., 1990). In such nosocomial infection, the organism is generally found as a biofilm attached to the surface of a device. Biofilms are protected from host defences by diffuse exopolymer slime layers (glycocalyx) of bacterial origin (Johnson et al. 1987; Gray et al., 1987). These slime layers also protect the sessile population from any major fluctuations in the macro-environment (Costerton et al., 1987) and from the

† Present address: Institute of Ophthalmology, Moorfields Eye Hospital, London, UK.

Abbreviation: EPS, exopolysaccharide. therapeutic effects of antibiotics such as tobramycin (Evans et al., 1990; Anwar et al., 1989) and vancomycin (Evans \& Holmes, 1987).

The biofilm mode of growth is recognized as being of prime importance in the establishment and maintenance of bacterial populations within a wide variety of natural habitats, including infections and colonization of medical devices (Gristina et al., 1987; Marrie et al., 1982). Resistance of device-associated infections has been variously attributed to failure of antibiotics to penetrate the glycocalyx (Nickel et al., 1985), slow growth rates within nutrient-deprived biofilms (Brown et al., 1988) and/or to innate properties of adherent cells (Evans \& Holmes, 1987). In this respect, close proximity of surfaces, whether chemically and nutritionally inert, nutritious and/or associated with other living cells, causes the expression of physiologies distinct from those of suspension cultures in the laboratory (Marshall et al., 1971; Gilbert et al., 1990; 
van Loosdrecht et al., 1990). Extracellular polysaccharide production is often derepressed (Deretic et al., 1989), extracellular enzymes may be influenced (Giwercman et al., 1991), and at a genomic level recent work has noted the presence of 'touch-promoters' (Dagostino et al., 1991).

Often such studies fail to take into consideration the effect of growth rate on the physiology of the organism and may fail to distinguish between characteristics unique to a biofilm mode of growth and those unique to slow growth (Brown et al., 1988). Growth of bacterial biofilms at controlled growth rates (Gilbert et al., 1989; Duguid et al., 1992a) and comparisons with chemostat culture have allowed these separate influences to be assessed for a number of Gram-negative (Evans et al., 1990, 1991) and Gram-positive (Duguid et al., 1992a, b) pathogens. Such studies have identified not only effects associated with adherence per se but also an overriding influence of specific growth rate and nutrient deprivation (Brown $e t$ al., 1990; Gilbert et al., 1990). Use of these techniques has not only shown reduced growth rates in biofilms to be a major contributor to their recalcitrance but also that cell division cycle modulates dispersal of the cells (Allison et al., $1990 \mathrm{a}, \mathrm{b}$ ) and susceptibility to quinolone (Evans $\mathrm{et}$ al., 1991) and aminoglycoside antibiotics (Evans et al., 1990).

The present study develops such approaches to growthrate control of Gram-positive biofilms and examines the separate influences of growth rate and adherence upon the production of extracellular virulence factors by $S$. epidermidis.

\section{METHODS}

Bacterial strain. Stapbylococcus epidermidis NCTC 11047 was used throughout. Stock cultures were maintained on Nutrient Agar (Oxoid CM 3) slants at room temperature in a darkened cupboard. The identity of the strain was confirmed by using the criteria and methods described by Schliefer \& Kloos (1975).

Continuous culture. Continuous cultures were established, at $37{ }^{\circ} \mathrm{C}$, utilizing a glass fermenter ( 1 litre, jacketed continuousculture vessel, 500 Series, LH Fermentation), a peptonesupplemented minimal-salts medium (Duguid et al., 1992a) and the methods described by Gilbert \& Brown (1978). The medium contained sufficient carbon source (glycerol, $10 \mathrm{mM}$ ) to allow batch growth to a stationary-phase $\mathrm{OD}_{470}$ of 1.0 with all other nutrients $\left[\left(\mathrm{NH}_{4}\right)_{2} \mathrm{SO}_{4}, 6 \mathrm{mM} ; \mathrm{MgSO}_{4}, 0.5 \mathrm{mM} ; \mathrm{KCl}, 13.5 \mathrm{mM}\right.$; $\mathrm{KH}_{2} \mathrm{PO}_{4}, 28 \mathrm{mM} ; \mathrm{Na}_{2} \mathrm{HPO}_{4}, 72 \mathrm{mM} ; 1 \mathrm{mg}$ thiamin l-1 $; 0.5 \mathrm{mg}$ biotin $\mathrm{l}^{-1} ; 0.5 \mathrm{~g}$ Peptone $\mathrm{P}^{-1}$ (Oxoid L49)] present to excess and the medium buffered to $\mathrm{pH} 7 \cdot 4$. The medium contained no added iron other than that present as trace contaminants. Supplementation of this medium with iron gave an increased grow th rate in batch culture, but no increase in stationary-phase cell-density. Whilst the medium restricts the extent of cell growth through carbon-source availability it is therefore also restrictive in iron and might cause the cells to express highaffinity iron-uptake systems.

Biofilm culture. Growth-rate-controlled biofilm cultures of $S$. epidermidis were established on cellulose acetate membranes according to the methods described by Gilbert et al. (1989) and Duguid et al. (1992a). Mid-exponential-phase cultures of $S$. epidermidis $\left(50 \mathrm{ml}, 1 \times 10^{8}\right.$ cells $\mathrm{ml}^{-1}$ ) were collected by pressure filtration $(6$ p.s.i., $41.4 \mathrm{kPa})$ onto the surfaces of $0.22 \mu \mathrm{m}$ pore- size cellulose acetate membranes ( $47 \mathrm{~mm}$ diam., Millipore). The membranes were removed from the pressure-filtration device (Millipore) and inverted into the base of the modified fermenter (Gilbert et al., 1989). The membranes were immediately perfused with fresh medium from their sterile sides at various controlled rates. Biofilms, which developed on the underside of the membranes, were shown to be relatively constant with respect to cell number $\left(1-2 \times 10^{9}\right.$ cells per membrane) over $100 \mathrm{~h}$. Steady-state flow rates of between 10 and $200 \mathrm{ml} \mathrm{h}^{-1}$ were found to govern the rate of evolution of dispersed cells in the perfusate and thereby the specific growth rate of the population. At flow rates of $>180 \mathrm{ml} \mathrm{h}^{-1}$, growth rates were maximal and at a value equivalent to $\mu_{\max }$ for the medium $\left(\mu_{\max }=0.42 \mathrm{~h}^{-1}\right)$. Cultures were equilibrated for $40 \mathrm{~h}$, at steady state, prior to collection of perfused medium/biofilms. Steady-state biofilms were removed from the fermenter, cut into quarters and placed in sterile phosphate-buffered saline $(0 \cdot 1 \mathrm{M}, \mathrm{pH} 7 \cdot 0)$. Samples were vigorously shaken for $10 \mathrm{~min}$ using a Griffin flask shaker. Preliminary experiments had determined that this released more than $99 \%$ of the cells from the membrane and that the majority ( $>99 \%$ ) were in suspension as single cells. Growth rates were calculated in each instance, with a knowledge of medium flow rate, from viable counts performed on the perfusates and resuspended biofilm (Duguid et al., 1992a).

Iron chelatcrs. Levels of iron chelators were assayed in culture supernatants according to the methods of Schwyn \& Neilands (1987). All glassware was washed thoroughly using a mild detergent (Lipsol, LIP), rinsed and soaked in consecutive baths of EDTA $(0 \cdot 01 \%, 24 \mathrm{~h})$ and $\mathrm{HCl}(0 \cdot 1 \mathrm{M}, 24 \mathrm{~h})$. Soaking was followed by four consecutive rinses in reverse-osmosis water. Viable counts were performed upon freshly collected spent medium eluted from the chemostat and biofilms at each steadystate growth rate. Spent culture medium was then collected onto ice for $1 \mathrm{~h}$ for both perfused biofilms and chemostat cultures. Samples were centrifuged $(1000 \mathrm{~g}, 15 \mathrm{~min})$ and supernatant fluids reduced in volume by $90 \%$ by freeze-drying. Equal volumes of the concentrate and reagent were mixed and left at $20^{\circ} \mathrm{C}$ for $1 \mathrm{~h}$. The reagent consisted of Cetrimide USP solution $(10 \mathrm{mM}, 6 \mathrm{ml})$, distilled water $(30 \mathrm{ml})$, iron chloride $(1 \mathrm{mM}$ in $10 \mathrm{mM} \mathrm{HCl}, 1.5 \mathrm{ml}$ ) and chrome azurol $\mathrm{S}(2 \mathrm{mM}, 7.5 \mathrm{ml})$. These were mixed together and anhydrous piperazine $(4.31 \mathrm{~g}$ dissolved in $20 \mathrm{ml}$ acidified water) added. The volume was adjusted to $100 \mathrm{ml}$ and sulfosalicylic acid $(101.6 \mathrm{mg})$ dissolved within it.

The $A_{630}$ was related to that of similarly treated samples of fresh culture medium. The iron chelator content of the samples was given by the reduction in $A_{630}$ of the samples and was related to viable cell count.

Protease assay. Protease activity within concentrated culture supernatants was assayed using heat-denatured casein as the substrate and a method based on that described by Wretlind \& Wadstrom (1977). Aliquots of concentrated culture supernatant $(1.0 \mathrm{ml})$ were warmed to $37^{\circ} \mathrm{C}$ and added to the reaction mixture $\left[2 \mathrm{ml} 1.5 \mathrm{~g}\right.$ heat-denatured casein $l^{-1}$ in phosphatebuffered $(0.05 \mathrm{M}, \mathrm{pH} 7.4)$ calcium chloride] and incubated at $37^{\circ} \mathrm{C}$ for $1 \mathrm{~h}$. Perchloric acid $(3 \mathrm{ml}, 1 \mathrm{M})$ was added to stop the hydrolysis and the $A_{280}$ read on a spectrophotometer. Protease activity was calculated as the $A_{280}$ increase and related to viable count.

Exopolysaccharide (EPS) assay. EPS production was quantified using the methods described by Dall \& Herndon (1989). Total counts were made, using a haemocytometer slide, on test suspensions taken directly from the chemostat and prepared from steady-state biofilms at various growth rates. Biofilms were dispersed from their cellulose-membrane supports by vigorous shaking (10 $\mathrm{min})$, as described above. 
Volumes of resuspended biofilm and/or planktonic culture $\left(5 \mathrm{ml}, 1 \times 10^{8}\right.$ cells $\left.\mathrm{ml}^{-1}\right)$ were centrifuged $(1000 \mathrm{~g}, 15 \mathrm{~min})$ in a Beckman J2-21 centrifuge. The resultant pellets were resuspended in sterile saline $(1 \mathrm{ml})$ and sonicated $(2 \mathrm{~min}, 60 \mathrm{~W}$ power) using a Soniprep 150 (MSE). The samples were further centrifuged $(1000 \mathrm{~g}, 10 \mathrm{~min})$ to remove cells, and the supernatant added dropwise to absolute alcohol $\left(10 \mathrm{ml}, 4^{\circ} \mathrm{C}\right)$. After $24 \mathrm{~h}$ at $4{ }^{\circ} \mathrm{C}$, the precipitated EPS was collected by centrifugation $(10000 \mathrm{~g}, 20 \mathrm{~min})$, resuspended in sterile water $(1 \mathrm{mi})$, mixed with conc. $\mathrm{H}_{2} \mathrm{SO}_{4}(77 \%, 7 \mathrm{ml})$ and transferred to a boiling tube in an ice bath for $10 \mathrm{~min}$. Cold tryptophan $(1 \%$, $\mathrm{w} / \mathrm{v} ; 1 \mathrm{ml}$ ) was added and the tubes heated in a boiling bath for $20 \mathrm{~min}$ to effect hydrolysis. Acid hydrolysis of EPS produces a furan which condenses with the tryptophan to produce a coloured product. This may be quantified, after cooling, by measuring $A_{500}$. Calibration curves were prepared against standard dextran solutions. Preliminary experiments had determined that solutions of hexose and pentose sugars, disaccharides, DNA and protein did not interfere with the assay. All determinations were performed in triplicate upon a minimum of two separate samples. Results were expressed as dextran equivalent units per $10^{8}$ cells.

\section{RESULTS AND DISCUSSION}

\section{Effect of specific growth rate on production of siderophores and protease enzymes}

The effects of specific growth rate upon the production of protease enzymes and siderophores by planktonic and biofilm cultures of $S$. epidermidis are presented in Figs 1 and 2 , respectively. Unlike batch cultures, in continuous culture secondary metabolites and extracellular products are subject to constant dilution by the addition of fresh medium. At steady states, production of such factors by

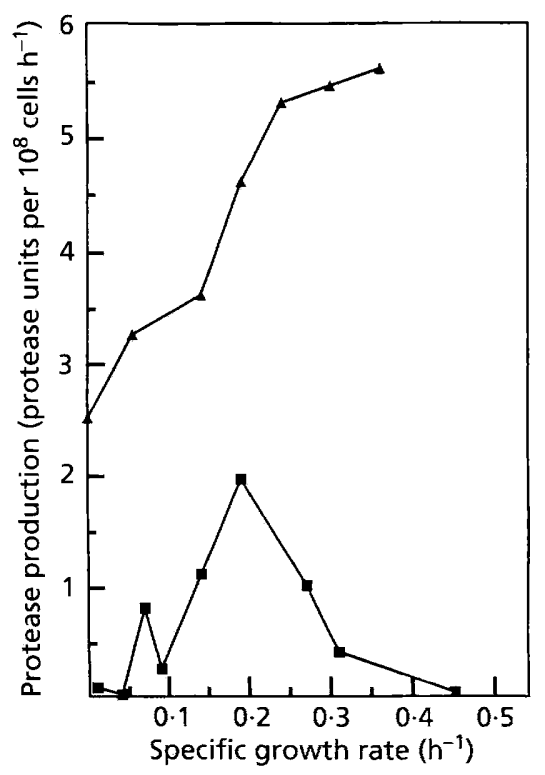

Fig. 1. Effect of specific growth rate upon the production of protease by adherent biofilms ( $\mathbf{A}$ ) and planktonic populations (a) of S. epidermidis grown in a peptone-supplemented simple-salts medium containing no added iron. the resident population equals their rate of removal/ dilution. In chemostats the dilution effect is readily calculated from a knowledge of the culture volume and the flow rate of fresh medium. In vitro biofilms, as employed in the present study, are perfused with fresh medium. Whilst the rate of removal of extracellular products can be readily determined by assay of the spent medium, dilution effects within the body of the biofilm cannot be calculated without knowledge of the biofilm volume. Steady-state levels of extracellular products within the spent medium are not therefore equivalent. In order to make direct comparisons between the two modes of growth in the present study the units for each were expressed as productivities (units per $10^{8}$ cells $^{-1}$ ) relative to the resident population in the chemostat and within the biofilm, respectively.

Extracellular protease production (Fig. 1) increased significantly with increases in growth rate for the biofilm cultures and in all cases was greater than for chemostat populations growing at the same growth rate. Protease production by the planktonic chemostat cultures was maximal at intermediate growth rates (about 0.15$0.25 \mathrm{~h}^{-1}$ ) and in no instance exceeded the productivity of biofilms.

The medium used in these studies contained no added iron and utilized Analar-grade reagents (BDH). Whilst control of growth rate was through limitation of the availability of carbon substrate, iron availability was sufficiently low to cause the expression of an iron-deprived phenotype. Iron chelators, presumed to be siderophores, were therefore produced during the growth of these cultures. The production of iron chelators by these biofilm cultures increased with growth rate (Fig. 2) and was significantly greater than for planktonic populations of cells. In contrast, iron chelation in chemostat cultures was greater at the slower growth rates. Such productivity was at a constant level of about 1.6 units per $10^{8}$ cells $^{-1}$ at growth rates of between 0.02 and $0.1 \mathrm{~h}^{-1}$ and about $0 \cdot 02$ units per $10^{8}$ cells $h^{-1}$ at faster growth rates. Similar dependence of siderophore production on growth rate has been reported for Klebsiella pneumoniae (Lodge et al., 1986), when, under various levels of iron availability in continuous culture, siderophore levels and also expression of a $39 \mathrm{kDa}$ peptidoglycan-associated protein increased with growth rate. The iron-chelation assay employed is not necessarily indicative of the production of siderophores, giving only a measure of the total iron-binding capacity of the culture supernatant. Whilst the results might therefore imply an induction of a high-affinity uptake mechanism for iron-associated siderophores at the faster growth rates, where presumably iron requirements by the cells are greatest, they might also indicate the production of weak iron chelators such as phosphate or organic acids. If it is assumed that the iron chelation comes from the production of siderophores then leaching from the biofilm cultures will dramatically reduce their effectiveness as an iron-uptake system. Greatly enhanced productivities of siderophores at the faster growth rates, when exopolymer deposition around the cells is reduced, might be as a response to severe iron deprivation. 


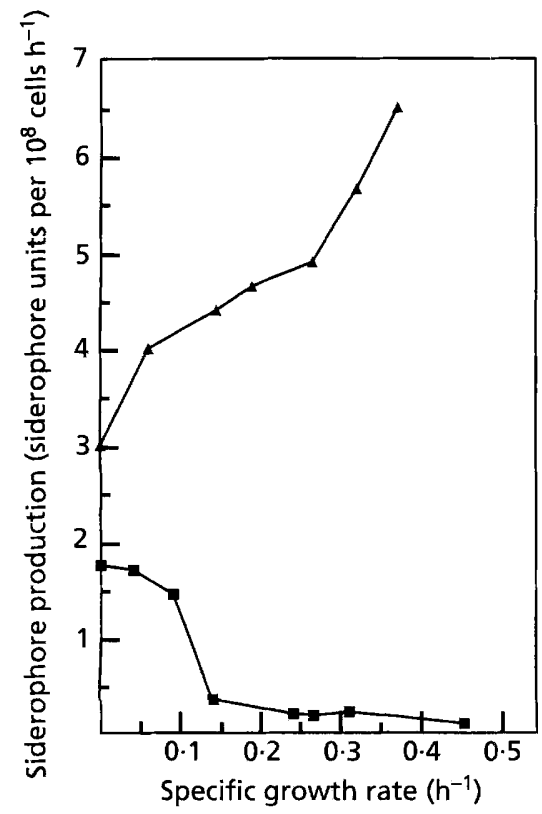

Fig. 2. Effect of specific growth rate upon the production of siderophores by adherent biofilms $(\boldsymbol{\Delta})$ and planktonic populations $(\boldsymbol{\square})$ of $\boldsymbol{S}$. epidermidis grown in a peptonesupplemented simple-salts medium containing no added iron.

Iron chelator and protease production do not appear from the above data to be co-induced either in biofilms or planktonic culture. Such might be the case if a function of proteases were to liberate iron from naturally occurring iron carriers such as transferrin and lactoferrin (Griffiths, 1983).

Giwercman et al. (1991) reported that biofilms of Pseudomonas aeruginosa were less susceptible to $\beta$-lactaminduced production of $\beta$-lactamases than were planktonic populations. They attributed this, at least in part, to reduced growth rates of the biofilm relative to the planktonic cells, and in part to trapping of the $\beta$-lactamase within the glycocalyx. In the present study it would appear that not only do attached populations have greater productivity of proteases than planktonic cells but that this productivity increases as exopolymers become less abundant within the biofilm and presumably entrapment of the enzyme decreases.

\section{Effect of specific growth rate on EPS production}

Levels of EPS associated with the planktonic cells and with the biofilms were expressed, relative to dextran, as $\mu g$ per $10^{8}$ cells (Fig. 3). At specific growth rates approaching $\mu_{\max }$ the levels of EPS associated with planktonic and biofilm populations were similar. At slower rates of growth, however, EPS levels were markedly greater for the attached populations, in spite of growth under carbon-limitation. In $P$. aeruginosa, expression of a mucoid phenotype has been shown to be under the control of an environmentally responsive class of genes (Deretic et al., 1989). Similar classes of genes are

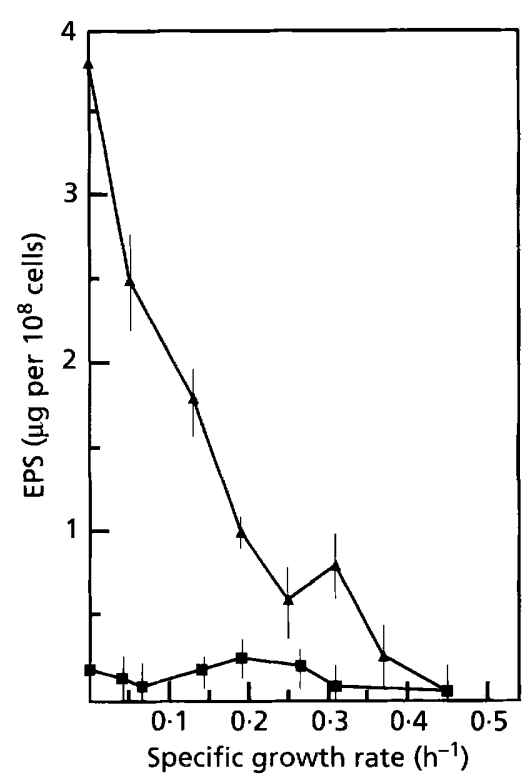

Fig. 3. Effect of specific growth rate upon the production of EPS by adherent biofilms $(\boldsymbol{\Lambda})$ and planktonic populations $(\boldsymbol{\square})$ of $S$. epidermidis grown in a peptone-supplemented simple-salts medium containing no added iron.

probably associated with EPS production in staphylococci. Indeed, levels of EPS associated with the biofilm cells were inversely related to their specific growth rate/medium perfusion rate. Analysis of collected cells which had dispersed spontaneously from the biofilms showed them to have similar levels of EPS associated with them as the chemostat-derived samples. Such results are compatible with the notions that attachment induces EPS production at rates which are inversely proportional to growth rate and/or that EPS is preferentially retained by the attached cells on division and release of a daughter cell to the culture eluate.

\section{Conclusions}

The evidence presented supports the view that attachment of $S$. epidermidis cells to surfaces and their formation into biofilm is associated with marked alterations in the production of extracellular virulence factors. Such changes will substantially alter the phenotype expressed in vivo following growth in association with indwelling devices.

\section{ACKNOWLEDGEMENTS}

This work was partly supported by the Cystic Fibrosis Research Trust (UK). E.E. acknowledges the receipt of an SERC Studentship.

\section{REFERENCES}

Allison, D. G., Evans, D. J., Brown, M. R. W. \& Gilbert, P. (1990a). Surface hydrophobicity and dispersal of $P$ seudomonas aeruginosa from biofilms. FEMS Microbiol Lett 59, 101-104. 
Allison, D. G., Evans, D. J., Brown, M. R. W. \& Gilbert, P. (1990b). Possible involvement of the cellular division cycle in dispersal of Escherichia coli from biofilms. J Bacteriol 173, 1667-1669.

Anwar, H., Dasgupta, M., Lam, K. \& Costerton, J. W. (1989). Tobramycin resistance of mucoid Pseudomonas aeruginosa biofilm grown under iron limitation. I Antimicrob Chemother 24, 647-655.

Brown, M. R. W., Allison, D. G. \& Gilbert, P. (1988). Resistance of bacterial biofilms to antibiotics: a growth rate related effect? J Antimicrob Chemother 22, 777-780.

Brown, M. R. W., Collier, P. J. \& Gilbert, P. (1990). Influence of growth rate on susceptibility to antimicrobial agents: modification of the cell envelope and batch and continuous culture. Antimicrob Agents Chemother 34, 1865-1868.

Costerton, J. W., Cheng, K. J., Geesey, G. G., Ladd, T. I., Nickel, J. C. \& Dasgupta, M. (1987). Bacterial biofilms in nature and disease. Ann Rev Microbiol 41, 435-464.

Dagostino, L., Goodman, A. E. \& Marshall, K. C. (1991). Physiological responses induced in bacteria adhering to surfaces. Biofouling 4, 113-119.

Dall, L. \& Herndon, B. (1989). Quantitative assay of glycocalyx produced by viridans group streptococci that cause endocarditis. $J$ Clin Microbiol 27, 2039-2041.

Deretic, V., Dikshit, R., Konyecsni, W. M., Chakrabarty, A. M. \& Misra, T. K. (1989). The algR gene, which regulates mucoidy in Pseudomonas aeruginosa, belongs to a class of environmentally responsive genes. J Bacteriol 171, 1278-1283.

Duguid, I. G., Evans, E., Brown, M. R. W. \& Gilbert, P. (1992a). Susceptibility of Stapbylococcus epidermidis biofilms towards ciprofloxacin: influence of specific growth rate and cellular division cycle. J Antimicrob Chemother 30, 791-802.

Duguid, I. G., Evans, E., Brown, M. R. W. \& Gilbert, P. (1992b). Effect of biofilm culture upon the susceptibility of Staphylococcus epidermidis to tobramycin. J Antimicrob Chemother 30, 803-810.

Evans, R. C. \& Holmes, C. J. (1987). Effect of vancomycin hydrochloride on Staphylococcus epidermidis biofilm associated with silicone elastomer. Antimicrob Agents Chemother 31, 889-894.

Evans, D. J., Brown, M. R. W., Allison, D. J. \& Gilbert, P. (1990). Susceptibility of bacterial biofilms to tobramycin: role of specific growth rate and phase in the cell division cycle. J Antimicrob Chemotber 25, 585-591.

Evans, D. J., Brown, M. R. W., Allison, D. J. \& Gilbert, P. (1991). Susceptibility of Pseudomonas aeruginosa and Escherichia coli biofilms towards ciprofloxacin: effect of specific growth rate. $J$ Antimicrob Chemother 27, 177-184.

Fidalgo, S., Vazquez, F., Mendoza, M. C., Perez, F. \& Mendez, F. J. (1990). Bacteremia due to Staphylococcus epidermidis: microbiologic, epidemiologic, clinical and prognostic features. Rev Infect Dis 12, 520-528.

Gilbert, P. \& Brown, M. R. W. (1978). Influence of growth rate and nutrient limitation on the gross cellular composition of Pseudomonas aeruginosa and its resistance to 3 - and 4-chlorophenol. J Bacteriol 133, 1066-1072.

Gilbert, P., Allison, D. G., Evans, D. J., Handley, P. S. \& Brown, M. R. W. (1989). Growth rate control of adherent bacterial populations. Appl Environ Microbiol 55, 1308-1311.
Gilbert, P., Collier, P. J. \& Brown, M. R. W. (1990). Influence of growth rate on susceptibility to antimicrobial agents: biofilms, cell cycle, dormancy and stringent response. Antimicrob Agents Chemother 34, 1865-1868.

Giwercman, B., Jensen, E. T., Hoiby, N., Kharamzi, A. \& Costerton, J. W. (1991). Induction of $\beta$-lactamase production in Pseudomonas aeruginosa biofilms. Antimicrob Agents Chemother 35, 1008-1010.

Gray, E. D., Regelmann, W. E. \& Peters, G. (1987). Staphylococcal slime and host defences: effects on lymphocytes and immune function. In Pathogenicity and Clinical Significance of Coagulase Negative Staphylococci (Zentralbl Bakteriol Suppl 16), pp. 123-132. Edited by G. Pulverer, P. G. Quie \& G. Peters. Stuttgart: Gustav Fischer.

Griffiths, E. (1983). Availability of iron and survival of bacteria in infection. In Medical Microbiology, vol. 3, pp. 153-177. Edited by C. S. F. Easmon, J. Jeljasewitz, M. R. W. Brown \& P. A. Lambert. London: Academic Press.

Gristina, A. G., Hobgood, C. D. \& Barth, E. (1987). Biomaterial specificity, molecular mechanisms and clinical relevance of Staphylococcus epidermidis and Stapbylococcus aureus infections in surgery. In Patbogenicity and Clinical Significance of Coagulase-Negative Staphylococci (Zentralbl Bakteriol Suppl 16), pp. 143-157. Edited by G. Pulverer, P. G. Quie \& G. Peters. Stuttgart: Gustav Fischer.

Johnson, G. M., Regelmann, W. E., Gray, E. D., Peters, G. \& Quie, P. G. (1987). Staphylococcal slime and host defences: effect on polymorphonuclear granulocytes. In Pathogenicity and Clinical Significance of Coagulase-Negative Staphylococci (Zentralbl Bakteriol Suppl 16), pp. 133-142. Edited by G. Pulverer, P. G. Quie \& G. Peters. Stuttgart: Gustav Fischer.

Lodge, J. M. T., Williams, P. \& Brown, M. R. W. (1986). Influence of growth rate and iron limitation on the expression of outer membrane proteins and enterobactin by Klebsiella pneumoniae grown in continuous culture. $J$ Bacteriol 165, 353-356.

Marrie, T. J., Nelligan, J. \& Costerton, J. W. (1982). A scanning and transmission electron microscopic study of an endocardial pacemaker lead. Circulation 66, 1339-1349.

Marshall, K. C., Stout, R. \& Mitchell, R. (1971). Mechanisms of the initial events in the sorption of marine bacteria to surfaces. $J$ Gen Microbiol 68, 337-348.

Nickel, J. C., Ruseska, I., Wright, J. B. \& Costerton, J. W. (1985). Tobramycin resistance of Pseudomonas aeruginosa cells growing as a biofilm on urinary tract catheter material. Antimicrob Agents Chemother 27, 619-624.

Schliefer, K. H. \& Kloos, W. E. (1975). Isolation and characterisation of staphylococci from human skin. Int J Sys Bacteriol 25, 50-61.

Schwyn, B. \& Neilands, J. B. (1987). Universal chemical assay for the detection and determination of siderophores. Anal Biochem 160 , $47-56$.

van Loosdrecht, M. C. M., Lyklema, J., Norde, W. \& Zender, A. J. B. (1990). Influence of interfaces on microbial activity. Microbiol Rev 54, 75-87.

Wretlind, B. \& Wadstrom, T. (1977). Purification and properties of a protease with elastase activity from Pseudomonas aeruginosa. J Clin Microbiol 103, 319-327.

Received 12 May 1993; revised 1 July 1993; accepted 8 July 1993 